\title{
24-year Old Medical Student with Raynaud's Phenomenon
}

\author{
Lindsay S. Leech ${ }^{\mathrm{a}}$ and Julie L. Welch ${ }^{\mathrm{b}}$ \\ a Indiana University School of Medicine, Indianapolis, IN, USA \\ ${ }^{\mathrm{b}}$ Indiana University School of Medicine, Department of Emergency Medicine, \\ Indianapolis, IN, USA
}

\section{Visual case discussion}

A 24-year-old female medical student presented after standing for two hours in a cold operating room observing surgery with digits 2-5 on both bands pale and cool to touch ( Fig. 1 ). She described parasthesias and stiffness in those digits, and denied any other symptoms. Her other hand appeared similar. Roughly thirty minutes after exiting the operating room and treating her hands with external passive rewarming, the parasthesias diminished and the color began to return to her digits ( Fig. 2 ). Her past medical history is significant for extreme cold (or hypothermia) exposure and frostbite to her hands at the age of fourteen with residual hypersensitivity of her hands (or fingers) to cold temperature.

\section{Conflict of interest and authorship confirmation}

All authors have participated in (a) conception and design, or analysis and interpretation of the data; (b) drafting the article or revising it critically for important intellectual content; and (c) approval of the final version.

The article I have submitted to the journal for review is original, has been written by the stated authors, and has not been published elsewhere.

The image(s) that I have submitted to the journal for review are original, was (were) taken by the stated authors, and has not been published elsewhere.

This manuscript has not been submitted to, nor is under review at, another journal or other publishing venue.

This is the author's manuscript of the article published in final edited form as:

Leech, L. S., \& Welch, J. L. (2016). 24-year Old Medical Student with Raynaud's Phenomenon. Visual Journal of Emergency Medicine, 5, 5-6. https://doi.org/10.1016/j.visj.2016.03.003 
The authors have no affiliation with any organization with a direct or indirect financial interest in the subject matter discussed in the manuscript. 
Figure 1. Patient's hand immediately after exiting the operating room.

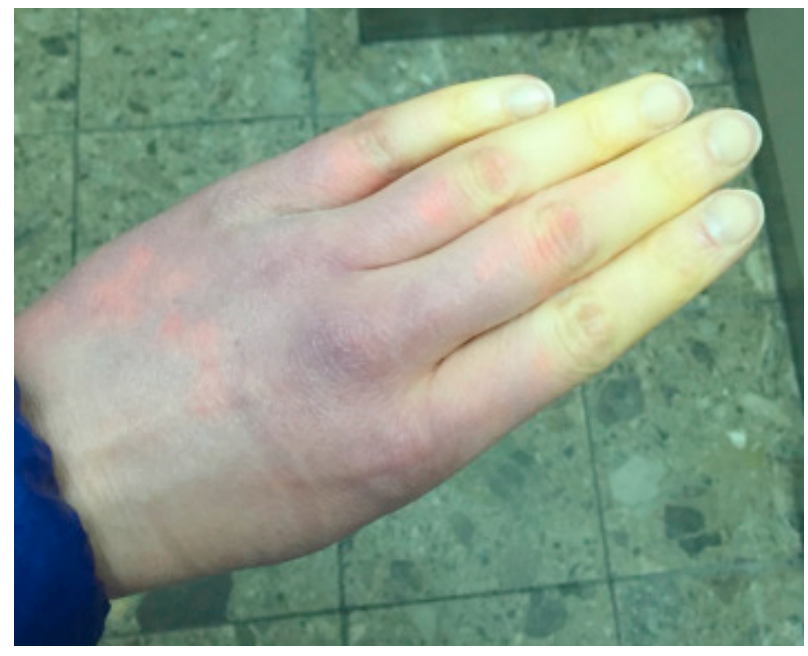


Figure 2. Patient's hand after external passive warming.

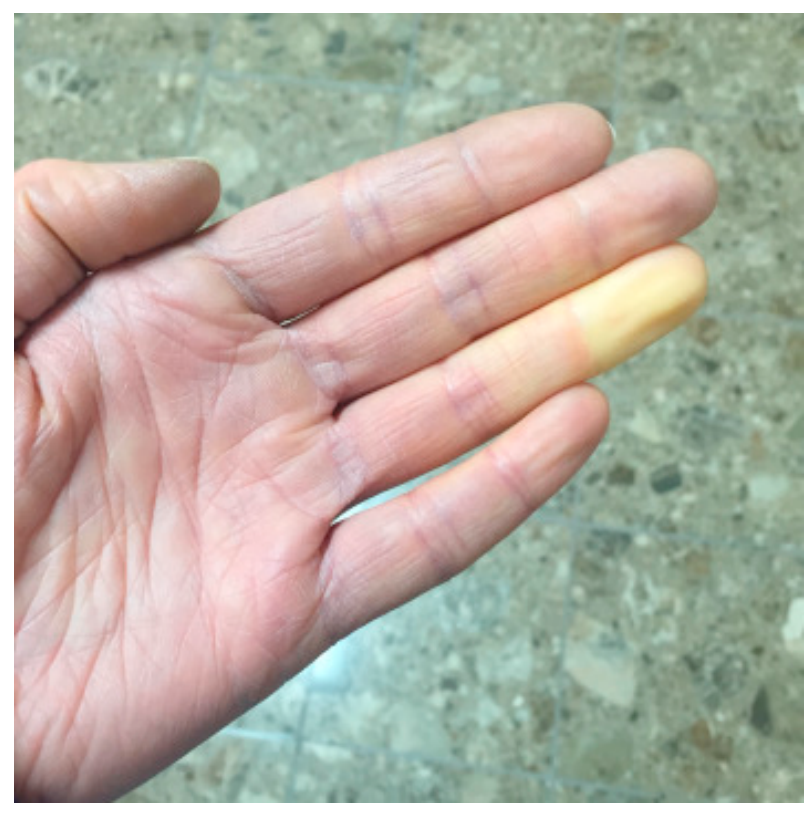

